Journal of Reproduction and Development, Vol. 40, No. 3, 1994

\title{
Decrease and Recovery of Ejaculated Sperm Concentration after Acute Testicular Gamma-Ray Irradiation in Cynomolgus Monkeys (Macaca fascicularis)
}

\author{
Masanori OKAMOTO \\ Laboratory of Animal Development, National Institute of \\ Radiological Sciences, 4-9-1 Anagawa, Inage-ku, \\ Chiba-shi 263, Japan
}

\begin{abstract}
After acute testicular irradiation in adult male cynomolgus monkey semen was periodically collected, and sperm concentration was examined as an index of radiation damage to the seminiferous epithelium. Sperm concentrations decreased after irradiation with 1, 2, or 3 Gy. Concentrations fell below the minimum normal level for unirradiated monkeys, $\left(10^{7} \mathrm{sperm} / \mathrm{ml}\right.$ of semen [13]) at 16.0, 8.5, and 8.0 weeks after irradiation, respectively. The lowest sperm concentration was observed 17.0,12.5, and 14.0 weeks after irradiation, and the percentages of the lowest sperm concentration relative to the pre-irradiation concentration were $1.20,1.37$, and $0.20 \%$, respectively. The sperm concentration recovered to pre-irradiation levels after 35.5, 36.5 and 41.0 weeks at doses of 1, 2 and 3 Gy, respectively. These results indicate that spermatogenesis decreases markedly after irradiation with 1-3 Gy but resumes after a definite period that depends on the radiation dose. Sperm concentration can be utilized as an effective index of radiation damage to the seminiferous epithelium and as an index of recovery.

Key words: Cynomolgus monkey, Sperm Concentration, Testicular acute $\gamma$-irradiation.
\end{abstract}

(J. Reprod. Dev. 40: 207-212, 1994)

E xperimental studies in nonhuman primates may provide important information in elucidating the genetic effects of ionizing radiation on humans. Therefore, rhesus monkeys, Macaca mulatta, have been widely used as experimental animals [1-4], although the rhesus monkey has a breeding season for reproduction [5]. Cynomolgus monkey, Macaca fascicularis, which belongs to the same genus Macaca, is a non-seasonal breeder in both laboratory-reared animals of feral origin and laboratory-bred animals [6, 7]. Therefore, this animal is a useful experimental model for physiological studies of human reproduction . We previously studied radiation induced chromosome ab-

Accepted for Publication: April 21, 1994.

Correspondence: M. Okamoto erration and morphological abnormalities of sperm in the ejaculate from the cynomolgus monkey [811]. Radiation damage to male germ cells in primates also was previously investigated in marmosets [12], rhesus monkeys [1-4] and cynomolgus monkeys [4]. However, these studies were primarily concerned with chromosome aberration and did not provide adequate information regarding impairment of testicular function and its recovery time, using sperm concentration as an index.

In the present study, to elucidate the effect of radiation on male germ cells, acute $\gamma$-ray irradiation of 1-3 Gy was administered to the testes of cynomolgus monkeys. After irradiation, semen was periodically collected to examine sperm concentration as an index of radiation damage to the seminiferous epithelium. The decrease in sperm 
concentration after irradiation and the time required for sperm concentration to recover to the pre-irradiation level were investigated.

\section{Materials and Methods}

\section{Animals}

Twelve adult male cynomolgus monkeys, Macaca fascicularis, more than 5 years of age and $4.0-7.1 \mathrm{~kg}$ in body weight were used in the experiments. All animals were of wild origin and had been maintained under laboratory conditions [13] at the Primate Research Facility of our institute for a period of 0.6 to 1.5 years prior to the experiments. The animals used in the present study were treated and /or handled according to the "Recommendations for Handling of Laboratory Animals for Biomedical Research," compiled by the Committee on Safety and Handling Regulations for Laboratory Animal Experiments of our institute.

\section{Irradiation}

Irradiation was performed on May 13 (animal Nos. 018, 020, 022, 023, 024, 025) and Oct 1 (animal Nos. 029, 033, 028, 030, 031, 032). Animals were anesthetized with ketamine hydrochloride and then exposed to local testicular acute irradiation with 1, 2, or $3 \mathrm{~Gy}$ of ${ }^{137} \mathrm{Cs} \gamma$-rays (dose rate of 0.25 $\mathrm{Gy} / \mathrm{min}$ ). Each dose level group consisted of 4 animals. Both testes of all animals were uniformly irradiated with the same dose, and the extra-testicular regions were shielded with lead.

\section{Semen collection}

Semen was collected using electroejaculation by rectal probe as described by Roussel and Austin [14 ]. The equipment and procedures used for this experiment were slightly modified as reported in previous papers [11, 13]. Just before irradiation, semen was collected twice or 3 times at intervals of 2 weeks from all animals to determine pre-irradiation sperm concentration levels. After irradiation, semen collections were carried out every 2 weeks until the sperm concentration returned to the pre-irradiation level.

\section{Examination of sperm concentration}

Semen volume was measured using the graduations on a conical tube. Samples for counting sperm concentration in the liquefied portion were prepared by removing the coagulum from the semen collected. The semen was then diluted with $0.5 \%$ gentian violet staining solution. The sperm concentration in each sample was measured with a Bürker-Türk hemocytometer.
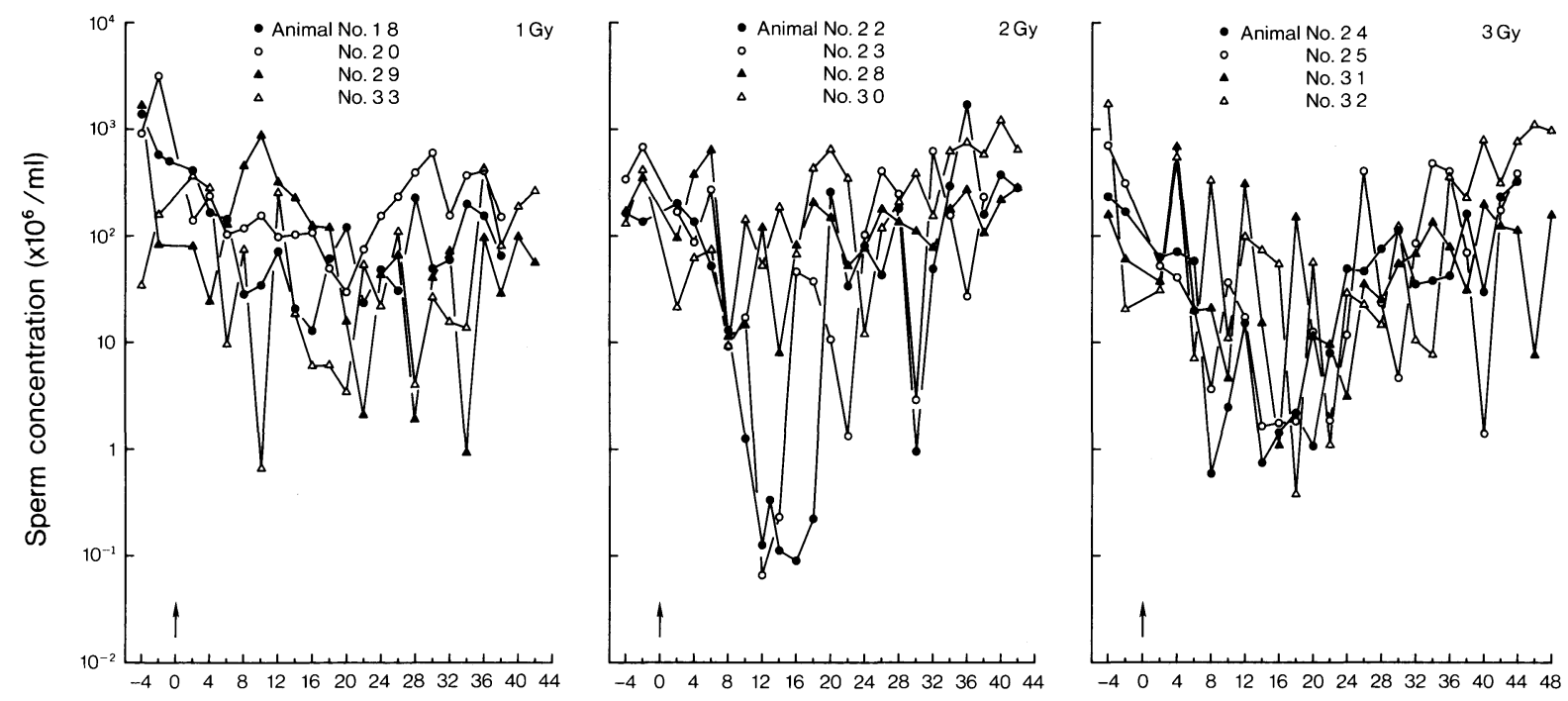

Weeks before and after irradiation

Fig. 1. Decrease and recovery of sperm concentration in semen samples of the cynomolgus monkey after testicular $\gamma$ irradiation. Arrows indicate the time irradiation. 
Table 1. Decrease and recovery time for spermatogenesis determined by sperm concentration after testicular $\gamma$-irradiation

\begin{tabular}{|c|c|c|c|}
\hline $\begin{array}{l}\text { Dose } \\
\text { (Gy) }\end{array}$ & Animal No. & $\begin{array}{l}\text { Time when sperm } \\
\text { concentration fell below } \\
\text { normal level* (weeks) }\end{array}$ & $\begin{array}{l}\text { Recovery time }{ }^{* *} \\
\text { (weeks) }\end{array}$ \\
\hline \multirow[t]{5}{*}{1} & 018 & $\dagger$ & 34 \\
\hline & 020 & $\dagger$ & 36 \\
\hline & 029 & 22 & 36 \\
\hline & 033 & 10 & 36 \\
\hline & & 16.0 & 35.5 \\
\hline \multirow[t]{5}{*}{2} & 022 & 10 & 36 \\
\hline & 023 & 8 & 38 \\
\hline & 028 & 8 & 36 \\
\hline & 030 & 8 & 36 \\
\hline & & 8.5 & 36.5 \\
\hline \multirow[t]{5}{*}{3} & 024 & 8 & 42 \\
\hline & 025 & 14 & 42 \\
\hline & 031 & 10 & 40 \\
\hline & 032 & 16 & 40 \\
\hline & & 8.0 & 41.0 \\
\hline
\end{tabular}

*Weeks after irradiation when the sperm concentration falls below the lowest normal level $\left(10^{7}\right.$ sperm $\left./ \mathrm{ml}\right)$. Annual sperm concentration variations in unirradiated monkeys range from $10^{7}$ to $10^{9} \mathrm{sperm} / \mathrm{ml}$ of ejaculated semen [13]. **Weeks after treatment for recovery to the pre-irradiation level of sperm concentration

†Sperm concentration is within the limits of $10^{7}$ to $10^{9} \mathrm{sperm} / \mathrm{ml}$ (Fig. 1).

\section{Results}

\section{Decrease in sperm concentration after irradiation}

Figure 1 illustrates the time course of changes in sperm concentrations until recovery to pretreatment levels in animals with acutely irradiated testes. Variations in normal sperm concentrations in unirradiated monkeys range from $10^{7}$ to $10^{9}$ sperm $/ \mathrm{ml}$ of ejaculated semen [13]; therefore, $10^{7}$ sperm $/ \mathrm{ml}$ was considered the minimum normal concentration. After irradiation with 1, 2, or $3 \mathrm{~Gy}$, mean sperm concentrations fell below this minimum normal level at $16.0,8.5$, or 8.0 weeks, respectively (Table 1 ). As the radiation dose increased, sperm concentrations decreased more rapidly. The sensitive period, when concentrations reached the lowest level, ranged from 10-22 weeks (mean 17.0, 1 Gy), 8-16 weeks (mean 12.5, 2 Gy), and 8-18 weeks (mean 14.0, $3 \mathrm{~Gy}$ ). The percentage of lowest sperm concentration to the pretreatment level (mean of the lowest concentrations after irradiation/mean of pre treatment levels) was $1.20 \%\left(11.81 \times 10^{6} / 981.26 \times 10^{6}\right)$ at $1 \mathrm{~Gy}, 1.37 \%(4.18$ $\left.\times 10^{6} / 305.87 \times 10^{6}\right)$ at $2 \mathrm{~Gy}$, and $0.20 \%\left(0.90 \times 10^{6} /\right.$ $\left.443.55 \times 10^{6}\right)$ at $3 \mathrm{~Gy}$.

\section{Recovery time to pretreatment sperm concentration}

After reaching the sensitive period with lowest concentrations, sperm levels gradually increased and finally recovered to pretreatment values. As shown in Table 1, after irradiation with 1, 2, or 3 $\mathrm{Gy}$, recovery to pretreatment sperm concentrations required 34-36 weeks, 36-38 weeks, and 40-42 weeks, respectively. Recovery time was delayed with increases in the radiation dose.

\section{Discussion}

Changes in the number of mature sperm after acute irradiation have been reported in mice [1517], hamsters [18], pigs [19], and humans [20] at dose ranges of 2-3 Gy, 2 Gy, 3 Gy and 1-6 Gy, respectively. These results showed that the time course of sperm number changes after irradiation was essentially similar in various mammals. The number of sperm decreased after irradiation, reached a minimal value, and then recovered to the pre-irradiation level. The radiation sensitive period and recovery time after irradiation in these 
experiments were dose dependent. These findings are supported by the present study of cynomolgus monkeys, and the time course of sperm concentration changes after acute irradiation shows a similar pattern to those of other mammals cited above. The decrease in sperm concentration was transient within a dose range of 1-3 Gy. Spermatogenesis resumed after a definite period depending on the dose, and sperm concentration recovered to the pre-irradiation level.

The relationship between the radiation sensitive period for sperm numbers and the cell generation during spermatogenesis was extensively studied in mice [21, 22] and humans [20, 23]. It was reported that radiosensitivity differs according to the cell generation during spermatogenesis. The highest radiosensitive cell generation was considered to be the spermatogonial stage, and radiosensitivity decreased with differentiation from spermatocytes to spermatids and then spermatozoa [20-23]. Thus, the sensitive period for sperm numbers observed in these studies [20-23] nearly corresponds to the highest sensitive stage of spermatogenesis, i.e., the spermatogonial generation.

The present study indicated that the earliest appearance of the minimum sperm concentration was 8 weeks after irradiation with 2 and 3 Gy (Fig. 1). It was also found that sperm concentration was less than the lower normal level for unirradiated monkeys $\left(10^{7}\right.$ sperm $\left./ \mathrm{ml}\right) 8.5$ or 8.0 weeks after 2 and $3 \mathrm{~Gy}$ irradiation (Table 1 ). The radiosensitive stage, according to the cell generation in spermatogenesis, has not been clarified in the cynomolgus monkey. Using the 12-stage classification procedure [25], Fouquet and Dadoune [24] estimated that the length of the seminiferous epithelial cycle was 10.5 days in cynomolgus monkeys, and the duration of spermatogenesis was approximately equal to 4 times the length of the seminiferous epithelial cycle, i. e., 42 days(6 weeks). Furthermore, taking the time required for sperm transport to the epididymis [26] and the ampulla ductus deferentis [13] into account, the total sperm transport time was estimated to be 2 weeks or longer. Therefore, sperm samples obtained by electroejaculation were at the beginning stage of spermatogenesis 8 weeks prior to collection. It is suggested that the spermatogonial stage is the most radiosensitive stage affecting decreased sperm concentrations in cynomolgus monkeys as observed in previous studies [20-23]. The decreased sperm concentrations that were observed in the present study were considered the result of cell destruction during the spermatogonial stage due to $\gamma$ irradiation. However, differences in the radiosensitivity of the various spermatogenic cells in the seminiferous tubule may have obscured the sensitive period and produced the wide time range for minimal sperm concentration occurrence at each dose level (Fig. 1). Annual variations in sperm concentrations in unirradiated monkeys occur not only among to different animals but also in the same animal [13]. These normal variations may also contribute to differences in the time required to reach minimal sperm concentrations.

We previously reported the time course of morphological sperm abnormality in irradiated monkeys [11]. The peak incidence after irradiation was 8 weeks at doses of 1 and 2 Gy and 6 weeks at a dose of $3 \mathrm{~Gy}$. The peak incidence of abnormal sperm occurred earlier than minimal sperm concentrations. Recovery time of abnormal sperm was 16 weeks at $1 \mathrm{~Gy}, 18$ weeks at $2 \mathrm{~Gy}$, and 22 weeks at $3 \mathrm{~Gy}$ and was also shorter than recovery of sperm concentration. The time course differences between sperm concentration and abnormal sperm may originate from differences in the highest radiosensitive spermatogenic cell generation of the 2 indices.

In conclusion, the present results revealed that impairment of the seminiferous epithelium after acute testicular irradiation with doses of 1-3 Gy is restored to the normal level after a definite period, that is dependent on the dose. The present study demonstrated that sperm concentration can be used as a simple, effective index of the testicular function impairment after irradiation as well as recovery. Recovery time in sperm concentration assay after irradiation is the most effective and reliable index to assess damage to spermatogenic cells among 3 values as follows: recovery time; lowest sperm concentration expressed as percentage of pre-irradiation value; and time that sperm concentration is less than $10^{7} \mathrm{sperm} / \mathrm{ml}$. Cynomolgus monkeys are a useful experimental model for radiobiological studies of genetic effects in humans.

\section{Acknowledgments}

The author thanks Dr. Takashi Yoshida, Tsukuba 
Primate Center for Medical Science, NIH, Tsukuba, and Prof. Tosiro Tiba, Faculty of Agriculture, Gifu University, Gifu, for their valuable comments and instruction. The author is also grateful to Dr. S. Nakai, the former director, for guidance and critical reading of the manuscript; to Dr. N. Yasuda, for helping with data analysis, Division of Genet- ics, NIRS; to Mr. M. Kitazume, head of our laboratory, for kind collaboration; and to Mr. T. Yamada and other staff members, for animal care and technical assistance. This work was undertaken as a research project, at the National Institute of Radiological Sciences "The assessment of risks for man to low-level radiation."

\section{References}

1. Lyon MF, Cox BD, Marston JM. Dose-response data for X-ray induced translocations in spermatogonia of rhesus monkeys. Mutation Res 1976; 35: 429-436.

2. van Buul PPW. Dose-response relationship for $X-$ ray-induced reciprocal translocations in stem cell spermatogonia of rhesus monkey (Macaca mulatta). Mutation Res 1980; 73: 363-375.

3. Wu C, Wang $Y$, Chen $X$, Liu Q. Effect of chronic irradiation of ${ }^{60} \mathrm{Co}-\gamma$-ray at low dose rate on rhesus monkey. Scientia Sinica 1982; 25: 376-383.

4. Adler I-D, Erbelding C. Radiation induced translocations in spermatogonial stem cells of Macaca fascicularis and Macaca mulatta. Mutation Res 1988; 198: 337-342.

5. Wickings EJ, Nieschlag E. Seanonality in endocrine and exocrine testicular function of the adult rhesus monkey (Macaca mulatta) maintained in a controlled laboratory environment. Int J Androl 1980; 3: 87-104.

6. Honjo S, Cho F, Fujiwara T, Yoshioka Y, Masuko K, Kurihara K, Yabe M, Noguchi Y. Breeding of cynomolgus monkeys through successive generations by indoor cage system. Jpn J Med Sci Biol 1978; 31: 301-310.

7. Honjo S, Cho F, Terao K. Establishing the cynomolgus monkey as a laboratory animal. In: Hendrickx AG (ed.), Advances in Veterinary Science and Comparative Medicine. Vol.28 Research on Non Human Primates. New York and London: Academic Press; 1984: 51-80.

8. Matsuda $Y$, Tobari I, Yamagiwa J, Utsugi $Y$, Kitazume M, Nakai S. $\boldsymbol{\gamma}$-Ray-induced reciprocal translocations in spermatogonia of the crab-eating monkey (Macaca fascicularis). Mutation Res 1984; 129: 373-380.

9. Matsuda $Y$, Tobari I, Yamagiwa J, Utsugi $Y$, Okamoto M, Nakai S. Dose-response relationship of $\gamma$-ray-induced reciprocal translocations at low doses in spermatogonia of the crab-eating monkey (Macaca fascicularis). Mutation Res 1985; 151: 121127.

10. Tobari I, Matsuda Y, Gu X, Yamagiwa J, Utsugi Y, Kitazume M, Okamoto $M$. Dose-response relationship for translocation induction in spermatogo- nia of the crab-eating monkey (Macaca fascicularis) by chronic $\gamma$-ray -irradiation. Mutation Res 1988; 201: 81-87.

11. Kitazume M, Okamoto $M$, Nakai S. Abnormal sperm in crab-eating monkeys after acute testicular $\gamma$-irradiation. J Radiat Res 1988; 29: 97-103.

12. Brewen JG, Preston RJ, Gengozian N. Analysis of X-ray-induced chromosomal translocation in human and marmoset spermatgonial stem cells. Nature (Lond) 1975; 253: 468-470.

13. Okamoto M. Annual sperm concentration variation in semen collected by electroejaculation in the cynomolgus monkey (Macaca fascicularis). Exp Anim 1994; 43: 25-31(in Japanese).

14. Roussel JD, Austin CR. Improved electroejaculation of primates and some properties of the semen. J Int Anim Tech 1968; 19: 22-32.

15. Searle AG, Beechey CV. Sperm-count, egg-fertilization and dominant lethality after $\mathrm{X}$-irradiation of mice. Mutation Res 1974; 22: 63-72.

16. Bruce WR, Furrer R, Wyrobek AJ. Abnormalities in the shape of murine sperm after acute testicular X-irradiation. Mutation Res 1974; 23: 381-386.

17. Meistrich ML, Samuels RC. Reduction in sperm levels after testicular irradiation of the mouse: A comparison with the man. Radiat Res 1985; 102: 138-147.

18. Okamoto M. Fertilizing ability in vitro of golden hamster spermatozoa after acute testicular X-irradiation. Exp Anim 1992; 41: 33-38 (in Japanese).

19. Willham RL, Cox DF. Sperm production in swine after exposure to X-irradiation. Radiat Res 1961; 59: 665-678.

20. Rowley MJ, Leach DP, Warner GR, Heller CG. Effect of graded doses of ionizing radiation on the human testis. Radiat Res 1974; 59: 665-678.

21. Oakberg EF. Effects of radiation on the testis. In: Astwood EB, Greep RO (eds), Handbook of Physiology. Vol. 5, The Male Reproductive System. Washington D C: Am Physiological Society, 1975; 233-243.

22. Meistrich ML, Hunter NR, Suzuki N, Trostle PK, Withers HR. Gradual regeneration of mouse testicular stem cells after exposure to ionizing radiation. Radiat Res 1978;74; 349-362. 
23. Clifton DK, Bremner WJ. The effect of testicular $X$-irradiation on spermatogenesis in man: A comparison with the mouse. J Androl 1983; 4: 387-392.

24. Fouquet JP, Dadoune JP. Renewal of spermatogonia in the monkey (Macaca fascicularis). Biol Reprod 1986; 35: 199-207.

25. Clermont Y, Antar M. Duration of the cycle of the seminiferous epithelium and the spermatogonial renewal in the Macaca arctoides. Am J Anat 1973; 136: 153-166.

26. Rowley MJ, Teshima F, Heller CG. Duration of transit of spermatozoa through the human male ductular system. Fertil Steril 1970; 21: 390-396. 